\title{
EL SABER ABSOLUTO: EN TORNO A LA INTRODUCCIÓN Y EL CAPÍTULO VIII DE LA FENOMENOLOGÍA DEL ESPÍRITU DE HEGEL
}

\author{
ABSOLUTE KNOWING: AROUND THE INTRODUCTION \\ AND CHAPTER VIII OF HEGEL'S PHENOMENOLOGY \\ OF SPIRIT
}

Alex Cárdenas Guenel*

\begin{abstract}
La presente Nota propone una reinterpretación del Saber Absoluto en Hegel, mediante una revisión interpretativa de la Introducción y el Capítulo VIII de la Fenomenología del espíritu. El Saber Absoluto es un término complejo que no está exento de una equivocidad en su interpretación, toda vez que dicho concepto se manifiesta como un momento culminante de la experiencia de la conciencia, en tanto aparecer del saber en su totalidad.
\end{abstract}

Keywords: saber absoluto, conciencia, experiencia, objetividad.

\section{Resumen}

This Note proposes a reinterpretation of the Absolute Knowing in Hegel, through an interpretive revision of the Introduction and Chapter VIII of the Phenomenology of spirit. The Absolute Knowing is a complex term that is not exempt from an equivocity in its interpretation, since this concept manifests itself as a culminating moment in the experience of consciousness, as it appears from knowing in its entirety.

Palabras clave: absolute knowing, consciousness, experience, objectivity.

Recibido: 202O-O8-I3 Aceptado: 202O-II-I7

* Doctorando en Filosofía, Universidada de Chile, E-Mail: alexcardenas@live.cl 
La Fenomenología del espíritu de Hegel, publicada en I807, es una de las obras más importantes en la historia del pensamiento occidental. Su dialéctica, en tanto que ciencia de la experiencia de la conciencia, es una autoexposición absoluta de la razón, cuyo despliegue viene a influir de manera decisiva en el desarrollo posterior de la filosofía. En términos generales, Hegel realiza una exposición sistemática del recorrido de la conciencia hacia la ciencia, mediante determinados momentos que configuran su camino, a saber: la conciencia -como certeza sensible, percepción y entendimiento-, la autoconciencia, la razón, el espíritu, la religión y, el saber absoluto en su aparecer. En primer término, la conciencia acontece como experiencia que ella realiza en su saber de sí misma. La concepción de sí misma de la conciencia es autoconciencia, la cual se despliega como un salir de sí hacia el objeto de su saber, lo absoluto. No obstante, es lo absoluto lo que se manifiesta en su aparecer como objeto en la conciencia. La síntesis de la conciencia y de la autoconciencia, es la razón -en su certeza de ser toda realidad-, la cual es elevada a la verdad como espíritu consciente de sí y del mundo. Luego, el contenido absoluto del ser otro para la conciencia, o la autoconciencia en cuanto espíritu que se sabe a sí mismo, es experimentado en la figura de la religión, por medio de su representación; pero, se eleva por sobre ella y la supera, mediante la manifestación del saber absoluto del espíritu en la conciencia, pues, el espíritu tiende a su manifestación en la realidad efectiva, puesto que su querer mostrarse constituye su esencia.

En la "Introducción" de la Fenomenología, consistente en dieciséis parágrafos, que cumplen el papel de ser una preparación al pensar de la obra que la introduce de un modo directo en el asunto en cuestión, Hegel, presenta en primer término lo dubitable de la representación natural del conocimiento en su querer conocer, como examen previo al adentrarse en la cosa misma. Esta preocupación en filosofía pareciera estar justificada de suyo. La representación natural en su corriente sentido común, tiende a representar el conocimiento como un instrumento para aprehender lo absoluto o, como un medio en el que éste se manifiesta. Hegel descarta las consecuencias lógicas de tales representaciones, por ser un contrasentido al pensar propiamente filosófico; porque, para conocer la efectividad de un instrumento o medio, se debería conocer previamente el objeto por conocer, lo cual presupone una relación cognoscente con el absoluto. Si bien Hegel no niega la posibilidad de un examen del conocimiento previo al filosofar; éste sólo se puede determinar a partir del saber mismo de lo que es en verdad. De manera que Hegel hace patente implícitamente la ingenuidad de la desconfianza 
epistemológica ante la cuestión ontológico-trascendental del absoluto, en tanto que el ser no está necesariamente vinculado al saber. No obstante, el conocer absoluto del absoluto se torna problemático.

El problema en cuestión, desde luego, pudiera llevarnos a una equivocidad en su interpretación, por eso necesariamente cabe preguntarse en primer término, qué es lo absoluto. Como posible esclarecimiento, cabe considerar lo que señala Fink (20II): "Lo absoluto no es ninguna cosa ni ninguna supercosa, no es ningún ente finito ni ningún dios infinito. Lo absoluto es el ser que acontece como pensar, devenir y aparecer" (p. 54). Entonces, este ser es un pensar, devenir y aparecer, que acontece de un modo absoluto. Pero, ¿qué significa que el aparecer del absoluto se manifieste de un modo absoluto? Sobre esto, Heidegger (I942) dilucida el concepto del absoluto en Hegel conforme al absolver de la absolución, es decir, absolver la mera apariencia del pensar que cree entrar en lo absoluto. El saber absoluto acaece en la absolvencia, como absolvente camino a sí mismo. El camino del absoluto que lleva a su aparición implica que la conciencia se absuelva, en tanto que el aparecer de su saber sólo es posible en su absolución. Sólo así, en el absolver mismo, el absoluto es alcanzado en las figuras de la esencia de la conciencia. Pero, no es la conciencia natural la que recorre un camino en pos de su verdad esencial, sino que el mismo absoluto toma su curso en razón de su aparecer en la conciencia como verdad en su totalidad. Este proceso por el cual el absoluto despliega su curso hacia su esencia, no acontece fuera de sí ni exclusivamente al final, sino desde el inicio del recorrido que parte con la certeza sensible de la conciencia y de ahí en cada paso de la conformación histórica de sus figuras esenciales. Este progresivo andar de la conciencia constituye el camino de la elevación hacia a la absolutez del absoluto.

Para ello, la conciencia es quien conforma en sí misma su regla de medida para su propio examen interior respecto de la verdad de su esencia, esto es, la autoconciencia. Dicho examen se corresponde con dos momentos determinantes en la conciencia: el concepto y el objeto. Si el concepto es el saber en cuanto objeto, tal como es para otro y, el objeto es la esencia o lo en sí o verdadero, el examen consistirá en la observación atenta de si el concepto corresponde o no al objeto. Pero si la denominación es de un modo inverso, a saber, lo en sí como concepto y, como objeto el concepto en cuanto objeto, entonces el examen consistirá en observar atentamente si el objeto corresponde o no a su concepto. Así, pues, el concepto y el objeto, el ser para otro y ser en sí mismo, son formas de la distinción de la conciencia. En este sentido, según Hegel (2010), "la 
conciencia es, por una parte, conciencia del objeto, por otra, conciencia de sí misma" (p. I57).

El que la conciencia se examine a sí misma, pareciera indicarnos que nuestra tarea como sujetos que contemplamos la experiencia de la conciencia, es ser meros espectadores en la realización de su propio movimiento en el devenir. En cuanto mirar el movimiento de la conciencia como experiencia, necesariamente conlleva preguntarse, en ese sentido: ¿qué entiende Hegel por experiencia de la conciencia? En principio, Hegel no concibe la experiencia como una percepción o el modo de conocer al ente, sino más bien, como el despliegue de los momentos de su esencia. La experiencia es un viajar de la conciencia que recorre un camino esencial de sus figuras, cuyo despliegue toma su curso en un doble sentido del andar, es decir, como experimentado y andado (Heidegger, I942). Esto se manifiesta como oposición dialéctica en su auténtica eficacia, la cual ocurre entre el saber-no real, como concepto no realizado y, el saber real, en cuanto concepto en su plena realización. No obstante, el saber no-real es ya la realización del saber real, en tanto que éste último aparece en el primero. El saber real es el saber realizado porque ha reconocido lo que de real había en el saber-no real. Así, el saber real viene a ser la negación del saber-no real, en su saber del concepto no realizado, cuya realización como negación, supone la no-verdad del saber que se consideraba real, volviéndose así, lejano en su realización conceptual, pero tornándose lo más real en cuanto penetración consciente de la no-verdad, que se nulifica en la serie de configuraciones del desarrollo real del concepto. En este sentido, la conciencia se encuentra a sí misma en su propio concepto. Ahora, el que todo esto no sea en cierto modo una ilusión de la conciencia o un solipsismo, es a partir de la pauta de la propia conciencia en el examen que confirma la correspondencia y examina el saber y la pauta (Leal, I970).

De este modo, la experiencia es un "pasar-por" de la conciencia que re-presenta su propio examen, mediante el movimiento dialéctico de la negatividad, a saber, en su triple sentido: la negación de la tesis en la antítesis, la cual es conservada y luego también es negada en la síntesis. Es así como la negatividad de la experiencia de la conciencia es un camino de duda, o un "camino de la desesperación", porque exige un continuo abandono de lo aparentemente alcanzado (Heidegger, I942). Este es el movimiento dialéctico de la experiencia, el cual según Hegel (20I0), hace surgir un "nuevo objeto verdadero" en la conciencia, que se despliega precisamente en dos objetos: "el uno el primer en sí, el segundo el ser-para-ella de este en sî" (p. I57). Esto significa que al considerar 
la experiencia de la conciencia mediante una figura como la intuición sensible, por ejemplo, en el escrito de esta Nota, es posible observar que esta Nota en cuanto objeto viene a ser el ente intuido en sí y al mismo tiempo intuido "para ella", es decir, para la conciencia. En el en sí se encuentra el ser-para-ella del en sí; de manera que el ser-para-sí es el ser objeto de la Nota en cuanto objeto, o sea, el objeto en su objetividad. Ergo, este "nuevo objeto verdadero", es la objetividad del objeto. Así, pues, el ser-para-la conciencia es el saber acerca de ella que en su intuir sensible determina el ser objeto del objeto. Por ello, el ser nuevo objeto, en su objetividad, es ser un verdadero objeto. Ahora bien, este segundo objeto constituye la nulidad del primer objeto. Entonces, el primer objeto en su ser nulo es lo no-verdadero, puesto que aún no surge su objetividad; sólo a partir de ésta, en la objetividad, el segundo objeto logra su ser verdadero. Sin embargo, lo verdadero del segundo objeto es a partir del despliegue de lo no-verdadero del primero, lo cual hace posible un "nuevo objeto verdadero" (Heidegger, 1942).

La objetividad, entonces, es el objeto de la experiencia de la conciencia, cuya novedad originaria es la autoconciencia como esencia de la conciencia. La experiencia, es la objetividad del objeto que la conciencia experimenta, siendo así, tanto un experimentar como lo experimentado. La experiencia es una transición de un objeto a otro de la conciencia, cuyo transitar ocurre como inversión en sí misma, lo cual no es un mero mirar o asumir, sino más bien, un intervenir nuestro. Pues, el mirar en la forma de la inversión de la conciencia, es la intervención que, al dirigir nuestra mirada en el manifestarse de la objetividad del objeto, redirige la mirada de la conciencia del objeto hacia la conciencia de los objetos. Así, se manifiesta la integridad del originarse de este nuevo objeto verdadero, el cual yace en la incondicionalidad originaria de la autoconciencia, es decir, en lo absoluto. Por ello, el regreso a sí mismo de la autoconciencia incondicionada aparece en su condicionamiento incondicionalmente condicionante, a saber, en la conciencia absoluta (Heidegger, 1993).

En el Capítulo VIII de la Fenomenología, Hegel señala que el objeto del saber absoluto, es el saber del saber puro, que se manifiesta en el devenir de los momentos o configuraciones de la conciencia, desde la unificación del ser-en-sí y del ser-para-sí en su integridad, es decir, como sí-mismo que-es-para-sí. El saber absoluto es el saber concipiente del espíritu en la objetualidad de su esencia, esto es, el saber de sí mismo mediante el concepto que se presenta en la conciencia. Este saber que acontece en la experiencia substancial y objetual de la conciencia se manifiesta como verdad sentida del espíritu. El espíritu en su propio 
movimiento hace emerger la forma de su saber para llegar a ser lo que es en sí. Desde su interioridad que se exterioriza al deshacerse de su apariencia, desciende en la simplicidad inmóvil de lo en sí, para contemplar como sujeto el movimiento de sus diferencias y así retornar a su propia unidad. Esto envuelve un continuo volver a iniciar-se en series sucesivas de una profundización en grados cada vez más altos, cuya meta es el saber absoluto en cuanto espíritu que se sabe espíritu. Por ello, el camino que conduce a esta meta, es "la historia comprendida conceptualmente" (Hegel, 20I0, p. 92I).

El que la conciencia posea en su interior una cosa que es para otra, o bien, que el momento del saber de la conciencia le sea inherente su determinidad, así como también, el que la cosa no sea sólo para la conciencia, sino que puede estar fuera de esta relación, o siendo en sí, como un momento de la verdad (Hegel, 20IO), da cuenta de una "objetividad subjetivamente determinada" (De La Maza, 2004, p. I06), en tanto que la separación sujeto-objeto de la representación de la conciencia, se despliega como una experiencia que está condicionada por la determinación subjetiva de ambas formas.

En Hegel, el ser-en-sí es el momento en que todas las cosas se aparecen. Ese momento originario constituye toda realidad que se halla en proceso. Así, despliega su tránsito, del ser-en-sí al ser-para-sí, como serfuera-de-sí y en ser-cabe-sí, desembocando en la unidad de ser-en-y-para-sí, como retorno a ser en sí mismo espíritu. El ser-en-y-para-sí es el en sí mismo de la objetividad, que a su vez, es subjetividad en su forma conceptuante y conceptuada. Esta es la culminación del proceso originario de "sí-misma-ción" del espíritu en su saber absoluto (Marcuse, I970).

El absoluto llega a ser sí mismo en su devenir-se-otro para concebirse en el saber de su esencia y naturaleza. Su realidad efectiva es el espíritu expuesto en la aparición de su movilidad que deviene como saber absoluto, es decir, en ciencia como sistema. En primer lugar, la exposición sistemática de la obra, consiste en llevar al saber absoluto a sí mismo, a la región de su dominio; para luego, manifestar el despliegue de su dominio como realidad efectiva. Es así como las figuras de la conciencia son la manifestación de la historia absoluta del espíritu absoluto que acontece en el movimiento de su aparecer, como transmisión de una tradición que es asumida en su triple significación: tollere, conservare y elevare. Esto significa, según Heidegger (2008): "suprimir y eliminar la primera mera apariencia", luego "resguardar, llevar de fuera a dentro en la experiencia" y, "alzar a un nivel más alto del saber de sí mismo y de lo en él sabido" (p. 46). 
El desarrollo dialéctico es determinado por las determinaciones del pensamiento, en el pensarse-a-sí-mismo de la autoconciencia. Esto no es un mero saber de los entes, sino también, un saber del saber. El objeto que es sabido no puede separarse del sujeto que sabe, esto es, la verdad en la autoconciencia del saber absoluto. En este sentido, se supera la diferencia entre saber y verdad, mediante su mediación que surge al final, en la figura del saber absoluto. Es así como la Fenomenología es el camino de elevación de la conciencia común a conciencia filosófica, toda vez que es abolida la fisura entre conciencia y objeto, que se sitúa en la conciencia, a nivel de ciencia. Por ello, una introducción precedente a la ciencia no es posible ya que el pensamiento inicia consigo mismo con la decisión de pensar (Gadamer, 2000).

Este pensar, es un pensar ontológico porque el sí mismo se experimenta como ser, y el ser, como sí mismo, lo cual constituye el saber absoluto, cuyo objeto es el espíritu que se conoce a sí mismo. Lo absoluto estriba en la negatividad, esto es, en la negación de la negación. Esta experiencia se presenta como historia de la conciencia y por ende, como historia de su propia experiencia. El aparecer del saber absoluto sólo es posible en la medida que es llevado a la autoconciencia por el espíritu del mundo en la efectividad de su historia, cuyo devenir se actualiza en el saber fenoménico (Hyppolite, 1974).

El saber absoluto se caracteriza por su totalidad. En cada etapa se manifiesta una parte de su totalidad, hasta que en la última de todas las etapas se genera una integración de todas. Pero al mismo tiempo, llegar a esta totalidad del saber implica necesariamente sobrepasar la oposición sujeto-objeto, mediante la coincidencia del objeto del saber y el sujeto, es decir, relacionando el objeto del saber absoluto consigo mismo (Kojeve, 2013). El saber absoluto en su carácter procesual, se manifiesta como el horizonte que moviliza todo el proceso, cuyo motor impulsa al sujeto a no detenerse (Dri, 200I), esto es, en la comprensión de sí, que en clave antropológica y metafísica, implica saber -o al menos creer que se sabe-, que se está en un mundo exterior, pues, el hombre sin el mundo, es como un mundo sin el hombre, a saber, una abstracción inexistente. La comprensión de sí, es un tomar conciencia-de-sí y del mundo, superando el carácter parcial y fragmentario, en la coincidencia efectiva de ambas. Sólo así, sería posible alcanzar un saber total o absolutamente verdadero. Por tanto, el saber absoluto, viene a ser la realización de la ciencia por acción del hombre realizado objetivamente desde su yo-personal, que le es proporcionado por el espíritu y, que en efecto ha tomado conciencia de lo que él es (Kojeve, 2013). 
El contenido de la absolutidad del saber se torna problemático dada la dificultad de establecer su determinación total, puesto que ya desde la estructura de la representatividad en el saber religioso, es complejo determinar si al momento de su superación, el saber absoluto es también una figura propiamente tal, dentro de la configuración del recorrido que la conciencia efectúa o, como despliegue de la comprensión especulativa, es más bien una forma externa (Tufano, 2009).

Desde luego, esta forma en su radical inversión se manifiesta en lo absoluto, y éste no posee dependencia alguna, puesto que es su propio fundamento. No obstante, el saber absoluto, se entiende como la síntesis dialéctica entre espíritu y religión, de manera que el asunto estriba sobre la forma en que el saber absoluto ocurre, porque por una parte, la religión es en el modo de la trascendencia, mientras que el espíritu, es en el modo de la inmanencia. En este sentido, el saber absoluto parece ser la manifestación de una trascendencia inmanente. Por de pronto, la síntesis del saber absoluto emerge, en cuanto espíritu, en un proceso de culturización europea a partir de los griegos; mientras que la religión, emerge como la autoconciencia de dicha cultura que busca desarrollar sus más supremos ideales. Así, la síntesis del saber absoluto es una forma de reconciliación del ser con la conciencia, o del objeto de la conciencia con la autoconciencia, lo cual ocurre en la forma del en-sí y el para-sí, o entre lo dado y lo puesto, del saber del objeto como idéntico con el sujeto, esto es, la configuración de la identidad en la diferencia (Díaz, 2009).

En efecto, el saber absoluto en su devenir efectivamente real, acontece bajo la forma del aparecer que se corresponde a determinados momentos que configuran la experiencia de la conciencia, desde la certeza sensible, hasta al momento que culmina con el aparecer del saber en su totalidad (Fulda, 2007). El saber absoluto es un conocimiento de sí, que se hace patente en la coincidencia del sujeto que conoce y el objeto conocido, esto es, en la conciencia convertida en conciencia de sí -autoconciencia- que reconduce al ser como la propia verdad (De Fiore, 20I2). En definitiva, el espíritu busca manifestarse en la conciencia por medio de la razón que aspira al saber absoluto de sí mismo, cuyo despliegue ocurre en una forma de trascendencia inmanente de la realidad, como verdad constitutiva del ser. 


\section{Referencias bibliográficas}

Dri, R. (200I). La utopía que todo lo mueve. Hermenéutica de la religión y el saber absoluto en la Fenomenología del espíritu. Buenos Aires. Editorial Biblos.

De Fiore, L. (2012). La citta deserta. Leggendo il Sapere assoluto nella Fenomenologia dello spirito di Hegel. Roma: Lithos Editrice.

De La Maza, M. (2004). Lógica, Metafísica, Fenomenología. La Fenomenología del Espíritu de Hegel como introducción a la filosofía especulativa. Chile: Ediciones UC.

Díaz, J. (2009). "Lo absoluto del saber absoluto". Eidos, (II), IO-34.

Fink, E. (20II). Hegel. Interpretaciones fenomenológicas de la Fenomenología del espíritu. Trad. de Iván Ortega Rodríguez. Barcelona: Herder Editorial, S.L.

Fulda, H. (2007). "Das absolute Wissen - sein Begriff, Erscheinen und Wirklich-werden". Revue de métaphysique et de morale, 3(55), 338-40I.

Gadamer, H.G. (2000). La dialéctica de Hegel. Cinco ensayos hermenéuticos.

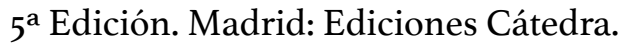

Hegel, G.W.F. (20I0). Fenomenología del espíritu. Ed. Bilingüe y trad. de Antonio Gómez Ramos. Madrid: Abada Editores, S.L.

Heidegger, M. (2008). La Fenomenología del espíritu de Hegel. Trad. de Manuel Vásquez y Klaus Wrehde. Madrid: Alianza Editorial.

(1993). "Erläuterungen der Einleitung zu Hegels Phänomenologie des Geistes (1942)". Hegel. Gesamtausgabe Bd. 68. Ed. Ingrid Schüssler. Frankfurt: Vitorio Klostermann.

- (1942). Dilucidación de la Introducción de la Fenomenología del espíritu de Hegel. Santiago de Chile: Edición electrónica de Philosophia - Universidad ARCIS.

Hyppolite, J. (1974). Génesis y estructura de la Fenomenología del espíritu de Hegel. Trad. de Francisco Fernández Buey. Barcelona: Ediciones Península.

Kojève, A. (2013). Introducción a la lectura de Hegel. Trad. de Andrés Alonso Martos. Madrid: Editorial Trotta.

Leal, F. (1970). "Comentario a la Introducción de la Fenomenología del Espíritu". Revista de Filosofía de la Universidad de Costa Rica, $8(26), 33-43$.

Marcuse, H. (1970). Ontología de Hegel y teoría de la historicidad. Trad. de Manuel Sacristán. Barcelona: Ediciones Martínez Roca, S.A.

Tufano, G. (2009). "El saber absoluto como problema en la Fenomenología del espíritu de G.W.F. Hegel”. Pensamiento. Revista de Investigación e Información Filosófica, 65(243), I6I-I75. 